\title{
Study of the Relationship between Personal Factors and Emotional Divorce
}

\section{Fatemeh Afrasiabi}

\author{
Department of Social Sciences, Payame Noor University (PNU), P.O. Box 19395-3697, Tehran, Iran
}

Mohammad Rahim Jafarizadeh

Department of Educational Science and Psychology , Payame Noor University (PNU), P.O. Box 19395-3697, Tehran, Iran

\author{
Doi:10.5901/mjss.2015.v6n6s6p406
}

\begin{abstract}
The purpose of this research is to evaluate the effect of individual factors on emotional divorce in "Behbahan" city. Method of research is based on the applied research and descriptive data collection methods. The Statistical population included all couples who went to family counseling centers and based on a review of these centers have been diagnosed with emotional divorce. 57 of those people were selected by simple random sampling and have been studied. A questionnaire survey was used to collect information and reach the goal of research. "Cronbach's Alpha Test" and number 0.911 represents reliability of the questionnaire and data were analyzed by APSS software. The results of research show that individual factors are not equally effective on an emotional divorce. There is a significant relationship between emotional divorce and these factors: sex, understanding spouse, using nice words by spouse, spouse expectations, understanding spouse situations and using drugs. But there is not any significant relation between emotional divorce and these factors: doubt and pessimism, misplaced expectations, occupational differences, age, educational differences, forced marriage.
\end{abstract}

Keywords: marriage, divorce, emotional divorce, personal factors

\section{Introduction}

Family, in terms of history is the most basic and in terms of expansion is the most cosmopolitan social institution (Khodayari and associates, 2007). Also family is the correlation cause, social equilibrium condition and the main pillar of the community (Fatehi Dehaqani \& Nazari, 2010). The family should be taken into consideration as much as possible and try to prevent family conflicts (Qa'emi, 2009). Stability and strength of a family depends on a stable marriage. It means that any instability and Disrupt laxity in marital satisfaction or lack of a successful marriage not only disrupt couple's mental relaxation, it also puts durability of the family at risk (Faqir Pour, 2002).

Marriage is the basis of family formation and that is in the opposite point of divorce. Divorce is a social innovation and is used to dealing with the failure of the marriage. Often in the process of divorce, one party suffers more because of emotional dependency and longer lives in crisis. Divorce leads to the personal dissolution of person, family and social life, and in most cases it has much more damage effects on women than men.

Experts believe that in most cases this happens during the divorce process: minor disputes, repetition of minor disputes, repetition of miffs, separation and reluctance of one spouse to the other, emotional divorce and finally legal divorce (Mohamadi, 2004).

One of the main challenges of emotional attitude which cause a lot of irreversible damages is emotional divorce because of misunderstanding about behavior, emotions and acts of spouse (Hobert, 2007). Emotional divorce is a hidden problem in life of many couples, although the couples are not officially separated, but they leave together without any love or good feeling, just like roommates (Ashrafi, 2009). Emotional divorce is the most important reason of family disruption, the most fundamental structure of society. In emotional divorce, the parties have no love and intimacy to each other, they are together but there is not any pleasure and satisfaction. Despite this lack of love they do not leave this kind of life (Ferdosi Pour, 2005). Sociologists consider emotional divorce as one of the social problems and increasing this factor leads to moral disorders, mess in family peace and finally social anomalies (Sotude, 2002).

Number of emotional divorce is twice the number of official divorce. It means that we have a lot of families with dark relations and incuriosity but they never go with divorce (Bokharayee, 2007). In fact, those marriages become a null life without love, companionship and friendship and couples just spend the time and go with the flow of family life (Steel Vakeid, 2009). About this case, there are different kinds of reasons such as: ethnic, social and cultural restrictions for 
example; Fear of public thoughts, fear of being alone, economic problems and raising children without any help. These reasons prevent from reaching the stage of official divorce (Bastani \& Associates, 2010).

Getting to the point of emotional divorce can have many different causes including: over working, financial problems, marital problems, inappropriate cultural and educational background, disagreement on spending leisure time and having entertainment. Also some personality traits such as: selfishness, greed, pride, diversity, diffidence and lack of self-esteem (Buss, D. M, \&. Shackelford, T. D, 2005). Mohbbi (2013) believes that the most important factors in the emotional divorce between women and men are: mismatch on couple's expectations especially in marital problems, lack of respect and, drugs and alcohol, lack of understanding issues related to marriage, poor communication and parents interference.

For a conclusion we can say emotional divorce can be a criterion of social ills in modern societies. Emotional divorce is the separation of man and woman, with the difference that they live together, they eat together, but they have no commitment to each other. In other words emotional divorce means to live under a common roof, without empathy and mutual interest. This procedure has detrimental effects on the individual and social behavior of children; also that is a serious threat for many Iranian families. This is considered as one of the effective factors on official divorce but families have no understanding of this social problem. Factors such as honor, concerns about the future of children, financial problems and so on are reasons that families do not have tendency to officially divorce (Sotoude, 2007).

So given that emotional divorce has an important role in endangering the security of the family and society, and considering this fact that emotional divorce is less scrutinized in comparison to official divorce, studying individual factors affective on emotional divorce helps a lot to a better understanding, prevention and treatment of this problem.

This research with the background of effective factors on couples intimacy and emotional separation based on an assumption that individual factors are one of the most important factors in family failure. Therefore studying and better understanding of this subject can be so effective on providing appropriate solutions and efficient decisions.

\section{The theoretical framework}

Various theories have been referring to this topic. A few of them are mentioned briefly:

\subsection{Structural functionalism:}

The main idea in this theory refers to the functions and activities for protection of society or social groups. According to Parsons playing professional roles for men and women can be a help to protect the family in the social system. Father plays an instrumental role as a liaison between the family and society and as a provider of financial needs of the family, and mother is representer of the family (Segalan, 2006).

In structural functionalism, when the family functions failed, the system is going to get dysfunctional problems. This situation refers to families have been failed in creation of values, cultural beliefs and social behavior. Dysfunctional family is a state of cluttered and disorganized families that shows disregard inattention to each other, conflicts, inappropriate behavior, and domestic violence (Mc Karti \& Edwards, 2011).

\subsection{Network Theory}

Network theory focuses on relations between spouses and their family network and it says the less family network relations, the more intimacy and commitment between couples. So if the network relations is too much, couples cannot make decisions, because they do it act based on network conditions and relations, and then they must accept the other's interference. This can lead to some conflicts and dissolution of the family is the result of the intervention of others (Moltafet, 2002).

\subsection{Social Prestige Theory (Social Stratification)}

According to this theory, people with different social prestige, have different expectations from the behavior of others. Also due to economic and social inequality families with different social prestige are not able to adapt with fast paced changes and then they will face to social anomalies (Roche, 1993). In this situation marital conflicts and then divorce occurs. Besides that, social database changes can also lead to disintegration of families. 


\subsection{Social Imagination Theory}

Emile Durkheim believes that individual ideas should be considered as a psychological issue (Herzlich, 1970). According to Alain Touraine, what we see is not matter, but how we see the topic is important (Touraine, 2000). It means that thought may not correspond with the reality; either it could be exactly part of reality. So, social imagination effects on people decisions, their social situation and their reaction on the issues that they face in society (Dois \& Paulmonari, 1986).

\subsection{Sexual Satisfaction Theory}

Sexual satisfaction is a condition that couples are happy and satisfied together (Winch \& Smith, 1974). They believe that sexual satisfaction is when current situation is exactly match with expected situation. Based on this definition sexual satisfaction happens when couple expectation is compatible with their real marital status.

\subsection{Cognitive Factors Theory}

There are increasing evidences that indicate the ways of perception, evaluation of couple from each other, and what happens in the relations between them have a significant effect on the quality of their relationship. According to this theory, people are always worried about irrational beliefs or unrealistic standards in their social communications, but these factors have adverse effects and irrational thoughts are reason of marital dissatisfaction.

\subsection{Personal characteristics Theory}

Individual differences do not lead to effective differences in satisfaction of relations, but two differences have significant effect on relationships problems and divorce: 1. Inability to control negative emotions 2. Insecure dependence styles (Attari \& Associets, 2005). They also mentioned that there is a positive relation between psychological factors and marital satisfaction and personal factors such as introversion.

\subsection{Individuality and Individual Differences Theory}

This theory refers to the better half of the couple's legend and it says this myth represent the wrong culture of marriage. Culture of flexible gender believes that by putting two human together we can have one perfect human. In other words total of two half would be a one (husband \& wife), however a half multiplied by a half would be a quarter, and obviously that is less than a half.

\section{Methods}

The purpose of this research is "studying the relationship between personal factors and emotional divorce in couples of Behbahan city". For reaching this purpose, a general question raised: What is role of each individual factor in emotional divorce in examined couples of Behbahan? This research is practical, and based on the descriptive method of data collection (or non-experimental). The Statistical population included all couples who went to family counseling centers in city of Behbahan and based on emotional divorce questionnaires which took by professionals of those counseling centers. Also the Statistical population included 178 people.

Sample size determined by "Cochran formula to determine the sample size" and significance level of 5\%, 62 person selected by simple random sampling. The information needed to answer the research question collected through questionnaires developed by researchers and SPSS software used to analyze statistical methods. Different kinds of statistical method were used such as: Descriptive statistics table, Pearson Correlation Coefficient \& t. Also reliability examined and evaluated through Cronbach's alpha coefficient and number 0.911 and that was approved.

\section{Results}

Descriptive section: The sample distributed by gender, age and occupation (Tables 1, Table2 and Table3 ) and represents the distribution alternate sample. 
Table 1: Sample distribution by gender

\begin{tabular}{c|c|c|c} 
Density & Percentage & Abundance & Gender \\
\hline 64.5 & 64.5 & 40 & Female \\
100 & 35.5 & 22 & Male
\end{tabular}

Table 2: Sample distribution by age

\begin{tabular}{c|c|c|c} 
Density & Percentage & Abundance & Age \\
\hline 50 & 50 & 31 & Less than 25 \\
64.5 & 14.5 & 9 & $30-26$ \\
85.5 & 21 & 13 & $31-35$ \\
85.5 & 0 & 0 & $36-40$ \\
100 & 14.5 & 9 & More than 40
\end{tabular}

Table 3: Sample distribution by Occupation

\begin{tabular}{c|c|c|c} 
Density & Percentage & Abundance & Occupation \\
\hline 46.8 & 46.8 & 29 & Unemployed \\
61.3 & 14.5 & 9 & Educational \\
64.5 & 3.2 & 2 & Management \\
74.2 & 9.7 & 6 & Engineering \\
100 & 25.8 & 16 & Other
\end{tabular}

\subsection{Inferential Section}

In this section relation between each individual factor and emotional divorce reviewed. According to the features of each factor test is done and based on results this question answered that if there is any relationship between the considered factors and emotional divorce.

Is there any relation between gender and emotional divorce?

Table 4: Test T, Relation between sexuality and emotional divorce

\begin{tabular}{|c|c|c|c|c|c|c|}
\hline \hline Level of Sig. & DF & Quantity of "t" & S.D. & Average score & Abundance & Gender \\
\hline \multirow{2}{*}{0.000} & \multirow{2}{*}{60} & \multirow{2}{*}{$4 / 132$} & $0 / 369$ & $4 / 078$ & 40 & Female \\
\cline { 5 - 7 } & & $0 / 375$ & $3 / 670$ & 22 & Male \\
\hline
\end{tabular}

Results, considering the difference between the two averages based on T test with (4.132) at a significance level of $99 \%$ and a significance level $(p=0.000)$, we can say there is a significant relationship between gender and emotional divorce. Is there any relation between Occupation and emotional divorce?

Table 5: Test T, Relation between occupation and emotional divorce

\begin{tabular}{||c|c|c|c|c|c|c||}
\hline \hline Level of Sig. & D.F. & Quantity of "t" & S.D. & Average score & Abundance & Occupation \\
\hline \multirow{2}{*}{0.442} & \multirow{2}{*}{60} & \multirow{2}{*}{$0 / 808$} & $0 / 399$ & $3 / 953$ & 51 & Different \\
\cline { 5 - 7 } & & $0 / 506$ & $3 / 84$ & 11 & Similar \\
\hline
\end{tabular}

Results, considering the difference between the two averages based on T test with (0.808) at a significance level of $99 \%$ and a significance level $(\mathrm{p}=0.422)$, we can say there is not any relationship between occupation and emotional divorce. Is there any relation between other individual factors and emotional divorce? 
Table 6: Pearson correlation coefficient on other individual factors and emotional divorce

\begin{tabular}{c|c|c|c} 
SIG & Correlation Coefficient & Abundance & Subject \\
\hline $0 / 642$ & $0 / 064$ & 62 & age \\
\hline $0 / 265$ & $0 / 144$ & 62 & Education differences \\
\hline $0 / 123$ & $-0 / 198$ & 62 & Forced marriage \\
\hline$/ 003$ & $0 / 369$ & 62 & Knowing the characteristics of spouse \\
\hline $0 / 005$ & $0 / 356$ & 62 & Using nice words \\
\hline$/ 05$ & $0 / 247$ & 62 & Inappropriate expectations \\
\hline $0 / 001$ & $0 / 423$ & 62 & Understanding of situation \\
\hline $0 / 567$ & $0 / 074$ & 62 & Doubt and pessimism \\
\hline $0 / 023$ & $-0 / 289$ & 62 & Drugs \& Alcohol \\
\hline
\end{tabular}

Results of Pearson Correlation Coefficient test represent the relationship between personal factors and emotional divorce and their differences.

Based on this table there is a significant relation between emotional divorce and these factors with 95 percent of reliability: Understanding the characteristics of spouse with correlation coefficient 0.369 and sig -0.003 , using nice words with correlation coefficient 0.356 and sig 0.005 , inappropriate expectations with correlation coefficient 0.247 and sig 0.05 , Understanding of situation with correlation coefficient 0.423 and sig 0.001and using drugs \& alcohol with correlation coefficient 0.289 and sig 0.023 . But there is not any relation between emotional divorce and these factors:

Age with correlation coefficient 0.064 and sig 0.642 , Education differences with correlation coefficient 0.144 and sig 0.265 , Forced marriage with correlation coefficient -0.198 and sig 0.123 , also doubt and pessimism with correlation coefficient 0.074 and sig 0.567 .

\section{Conclusion}

This study aimed to investigate factors affecting on emotional divorce and to provide guidelines for prevention in city of Behbahan. Emotional divorce is a kind of separation that couples lives together under one roof though, but there is no love between them. In this kind of life, the only thing that keeps couples together is the contract they accepted at the beginning of their marriage; of course at the time of signing the contract, they both felt love in their hearts. But after so many years, now this relationship is not sweet and warm anymore. In emotional divorce couples are not physically separated they live together under conditions. This occurs over time unilateral either bilateral and both parties begin to realize that they lost that attraction and good feelings in their life. In other words, the sensitivity and concern that they showed to each other begin to decrease. Such a problem in Iranian society is a result of changing traditional society to a modern society and of course it leads to disintegrating family relations, and decreasing nice and sweet moments in the family.

In such a situation, only the existence of specific reasons could keep couples stay together and in our country that reason is usually children or financial situation. Sociologists believe that when you love someone, you feel positive energy all around you and you feed all these good feelings to your spouse too, but if after some time man or woman start to be a narcissistic or impatient the other one start to have an incompatible reaction. When the couple found they are suffering and not trying to fix they would expect to have a bad relationship. Sociologists describe not fixed small conflicts as a reason of divorce and they also say at the first of married life couples have seemingly small differences for example cultural or attitude differences. If these problems do not get solved then they start to be bigger every day and by passing time there will be no intimacy, commitment or love anymore. Of course it they do not try to solve this problem finally emotional divorce happens. Based on results of this study there is a significant relation between emotional divorce and sexuality, knowing the characteristics of spouse, using nice words, expectations, understanding of situation, using drugs $\&$ alcohol. Generally, emotional divorce happens due to not meeting the emotional needs of the couples. Couples with emotional divorce, are aggressive and nervous, they also suffer from mental disorders. Emotional relationships are weak. Intimacy and support are all disappeared. Communications are not that much warm and peaceful. And these factors are all affective on emotional divorce. When there is lack of appropriate emotional relationships, there is no motivation to have a warm family. And this is the best time for emotional divorce to begin.

Study of successful and unsuccessful couple's lives indicates that how to have a relationship is one important aspect of these two groups' differences. Marital life can be affected by various factors, and some of them may lead to conflict, domestic violence, and emotional divorce and even officially divorce. The emotional divorce plays a serious role 
as a new variable of the official divorce. Clinical observations on counseling centers shows that couples especially women, suffer from lack of attention from their spouse. The main reason of emotional divorce is poor emotional communication skills. Of course several factors such as economic, social and family conflicts involved in the formation of emotional divorce.

In order to prevent the spread of this social problem its damaging effects, the following strategies can be recommended:

- Raising the level of social consciousness and literacy through classes like life skills classes in pre-marital health center, schools and universities.

- Raising awareness of family to meet the emotions of each other.

- Strengthening spiritual values

- Controlling the media and the creation of appropriate programs to raise awareness of families

- We cannot change people, but we must change our priorities. Couples are not supposed to look for guilty in their arguments. They are neither a judge nor a lawyer, but everyone should look for a way to solve the problem.

\section{References}

Attari , Y.A. Afzali, S. Mehrabizadeh, M. Comparison Marital Adjustment Consistency of Male Teachers in Ahvaz Schools on Sensation Seeking with their Wives." Journal of Education and Psychology of Shahid Chamran University, 2005 ;( 12$): 1$.

Bastani, S., Golzari, M. \& Roshani, Sh. Emotional Divorce; Causes and mediator conditions. " Journal of Study of Social Issues, 2010; (1): 3.

Buss, D. M, \&. Shackelford, T. D (2005), " How To Save A Marriage: Different Gender Strategies To Save Relationship ", Journal of Personality and Social Psychology, Vol. 72, No. 2.

Doise, W. palmonari, A. (1986). "Caracteristiaue des representations. Socials". Texte de base, L etude des representation socials. Paris

Herzlich, Claudine (1970)."Larepresentaion sociale. Introduction a .la psychologie social. Sociale .sous la direction deserge Moscivici, larousse, universite, sciences humanes et socials: Tom1, pp.303-325.

Hobert, d. (2007). Current Patterns of Parental Authority." Developmental Psychology Monographs, 4, (1), 1-103.

Tourraine, Alain; Khorokhavar, Farhad. (2000). la recherché de soidia -logue surle sujet. Fayard, September.

Winch, M. \& Smits, I. Perceived Parenting Dimensions and Identity Styles: Exploring the Socialization of Adolescence Processing of Identity-Relevant"Journal of Adolescence, 1974; 31(2), 151-164.

Steel L, Vakeid (2009)/ Sociology of family skills, Tehran, Azahra university publishers

Ashrafi, Farifte (2009)/ Sociological Study of emotional divorce, Master thesis, Olum Tahqiqat university

Bokharayee, Ahmad (2007)/ Sociology of lives in Iran (Emotional Divorce), Tehran, Pejvaak publishers

Khodayari, Shahabi (2007)/ the relation between religious attitudes and marital satisfaction in married students, Khanevade Pajouhi Magazine

Roche, Gay (1993)/ Social Changes, Translated by Mansour Vosouqi, Tehran, Ney publishers

Social pathology, Tehran, Avaye no publishers Sotoude, Hedayat (1379)/

Segalen, Martine (1370)/ Historical sociology of family, Translated by Mohsen Salalsi, Tehran, Markaz publishers

Segalen, Martine (2006)/ Historical sociology of family, Translated by Hamid Elyasi

Faqir Pour, Mansour, (2002)/ the role of social skills in marital compatibility \& Design an educational model, PHD thesis, Allameh University

Ferdosi Pour, Sima, (2005)/ Family Pathology, science course

Fatehi Dehaqani, Nazari, (2010)/ Sociological Analysis of the divorce attitude in Isfahan

Qa'emi Ali, (2009)/ Children \& Disturbed Family, PTA of Tehran

Mc Cartty, Jane Ribben, Edwards, Rosalind, (2011)/ Key Concepts in Family Studies, Translated by Mohamad Mahdi Labibi, Tehran

Moltafet Hossein, (2002)/ Studying of Affecting Factors on Couples Tend to Divorce in Darab City, Shiraz university, Master thesis, Sociology

Mohamadi, Z (2004)/ Survey of Women's Social Ills in 1370 \& 1380, Tehran, Women's social \& cultural council. 